\title{
Liver resection for intrahepatic cholangiocarcinoma in AJCC-stage IV: An evaluation of the survival benefit and prognostic accuracy of current AJCC staging system on $\mathbf{N}$ and $M$ classification
}

\author{
LEI YUAN $^{1 *}$, XIANWU LUO ${ }^{*}$, XINYUAN LU ${ }^{2}$, BIN HUANG ${ }^{3}$ and QUANYU CAI ${ }^{3}$ \\ ${ }^{1}$ The First Department of Biliary Surgery, Departments of ${ }^{2}$ Pathology and ${ }^{3}$ Medical Imaging, \\ Eastern Hepatobiliary Surgery Hospital, The Second Military Medical University, Shanghai, P.R. China
}

Received February 11, 2016; Accepted July 1, 2016

DOI: $10.3892 /$ or.2016.5103

\begin{abstract}
Intrahepatic cholangiocarcinoma (ICC) is usually confirmed in advanced stage at the time of diagnosis or after surgical exploration, however, indication of surgical treatment is usually controversial for ICC in advanced stages. This retrospective study aims to evaluate clinical value of surgery for such tumors, in order to identify the appropriate patients who will benefit from surgery, and to evaluate the prognostic accuracy of the current staging system for advanced ICC. From January 2007 to December 2011, 387 consecutive surgically treated patients with ICC in AJCC-stage IV were evaluated. Survival was compared among different patients grouped by different elements of AJCC staging system. The prognostic importance of extent of lymph node (LN) metastasis relative to the AJCC $\mathrm{N}$ and $\mathrm{M}$ classification system was assessed. Our data showed that survival was much better for patients in AJCC-stage IVA group (median survival time, MST, 9.0 months) than in AJCC-stage IVB group (MST, 5.0 months) $(\mathrm{P}<0.001)$. While in AJCC-stage IVB group, survival for patients in AnyTN2-3M0 subgroup (MST, 9.0 months) was
\end{abstract}

Correspondence to: Dr Lei Yuan, The First Department of Biliary Surgery, Eastern Hepatobiliary Surgery Hospital, The Second Military Medical University, 225 Changhai Road, Shanghai 200438, P.R. China

E-mail: icbbsuse@sina.com

${ }^{*}$ Contributed equally

Abbreviations: AJCC, American Joint Committee on Cancer; HBV, hepatitis B virus; HBsAg, hepatitis B surface antigen; ICC, intrahepatic cholangiocarcinoma; HCC, hepatocellular carcinoma; LN, lymph node; CA19-9, carbohydrate antigen 19-9; CEA, carcinoembryonic antigen; AFP, $\alpha$-fetoprotein; OS, overall survival; MST, median survival time

Key words: intrahepatic cholangiocarcinoma, staging, TNM classification, hepatic resection, prognostic factor much better than in AnyTNOM1 subgroup (MST, 3.0 months); and better than in AnyTN2-3M1 subgroup (MST, 4.0 months) $(\mathrm{P}<0.001)$. Overall, R0 and R1 liver resection should be indicated for patients in AJCC-stage IVA group and AnyTN2-3M0 subgroup in AJCC-stage IVB group, as patients in these groups will benefit from surgery with relatively better survival. Staging of advanced ICC by N2-3 instead of M1 for extended $\mathrm{LN}$ metastasis classification is superior in comparison with the AJCC staging system.

\section{Introduction}

Intrahepatic cholangiocarcinoma (ICC), the second most common primary liver cancer after hepatocellular carcinoma (HCC), has been categorized as mass-forming type, periductular infiltrating type and intraductal growth type according to category of the gross type (1). With a worldwide increase in the incidence rate in recent years (1-3), however, ICC remains less understood and always has worse prognosis compared with HCC (3-5), and practice guideline for treatment has not been universally accepted and thoroughly studied for ICC in advanced stage (6). It has been generally believed that surgical resection is indicated for all potentially resectable ICC for the benefit of better survival (3,6-10) and for the lack of other effective treatment options, but the prognosis remains dismal because the disease is usually advanced at the time of diagnosis or after surgery for quite a number of patients $(6,8,11)$. Up to $60 \%$ of ICC patients presented with disease in so advanced stage that made them not suitable for curative resection (3,6-8), as recurrence occurs frequently even after extended surgical resection $(6,8,10)$. Although recent studies suggest that curative/palliative resection can have beneficial impact on overall survival (OS) for some certain patients with advanced ICC $(6,8,10,12-14)$, the range or extent of ICC tumor in advanced stage justifying aggressive surgery, however, has not reached a consensus for surgeons in different countries.

Current studies of surgical treatments for ICC usually enrolled patients with tumors in all stages according to the 7th edition American Joint Committee on Cancer (AJCC) staging 
system (8,15-19). Owing to the relative paucity of this disease, most of the existing studies, however, usually involved small numbers of cases, spanned over a study period of decades, or were multicenter results with very small numbers per center, and in some studies patient inclusion was highly selective (concentrating on tumors in AJCC-stageI-III), leading to significant difference in OS among different studies and to controversies over surgical management of ICC especially in AJCC-stage IV. So, there is an increasing need for more comprehensive and more close data from large series to determine exact role of surgical treatment for ICC in AJCC-stage IV. In this retrospective study, we investigated surgical outcome, survival and the prognostic factors in a large series of consecutive patients with ICC in AJCC-stage IV at the time of diagnosis or after surgery (all of tumors were locally advanced but potentially resectable preoperatively) between 2007 and 2011 at a single institution, with the aim to evaluate safety and efficacy of surgical treatment, and the prognostic accuracy of AJCC staging system for patients with ICC in stage IV, and among which, to identify who would benefit from surgery.

\section{Patients and methods}

Patient recruiting and data collection. All consecutive patients with ICC who were admitted to the Eastern Hepatobiliary Surgery Hospital, a high-volume center in China, for initial surgical treatment from January 2007 to December 2011, were retrospectively reviewed. Inclusion criteria included the following: no history of previous anticancer therapy; no history of other malignancies; no severe comorbidity that can affect survival or act as contra-indications for surgery; all the tumors were locally advanced but potentially resectable preoperatively, and were proven to be in stage IV according to AJCC staging system at the time of diagnosis or after surgery; all of the cases were histopathologically proven. Exclusion criteria were as follows: hilar or extrahepatic cholangiocarcinoma; mixed type of primary liver cancer; intraductal growth type or periductal infiltration type of ICC (because the case numbers of the other two pathological type were very small and bio-characteristics of the other two types were different from mass-forming type); definite distant metastasis before operation (localized/diffuse occult distant metastasis within abdomen were sometimes found during surgical exploration, and some of such patients obtained resection); and incomplete clinical or survival data (Fig. 1). Demographic data for all patients, including age, gender, symptoms, underlying liver diseases, image findings, and laboratory test were collected. This study was approved by the local Ethics Committee.

Preoperative workup and surgery. Routine preoperative workup consisted of, but was not limited to, ultrasound scanning, three-phase computed tomography (CT) or magnetic resonance imaging (MRI) of the liver, endoscopic examination and laboratory tests. Patients underwent surgical exploration if preoperative image indicated a potentially resectable ICC and there were no general contra-indications for surgery. However, radiographic studies had a limited ability to determine respectability. Most of the liver resections were carried out under vascular control, and both anatomical and non-anatomic hepatectomy were performed depending on the size and location

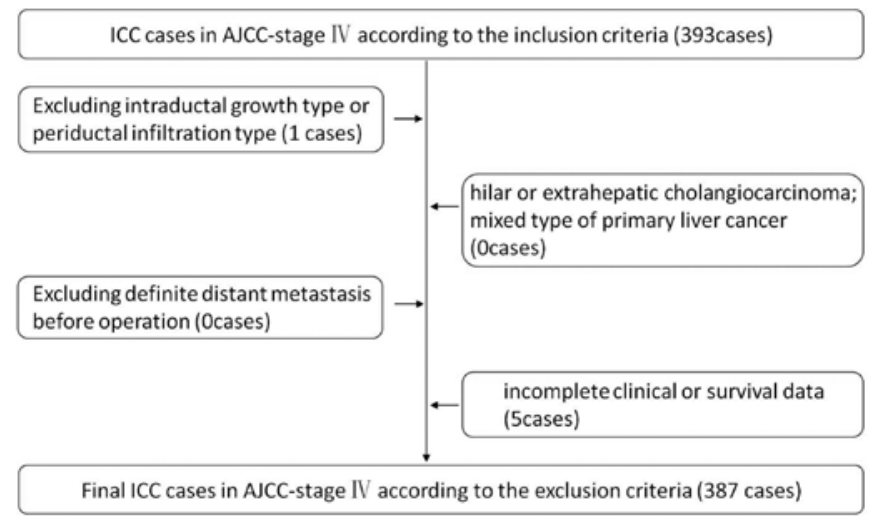

Figure 1. Flow chart of the patients excluded for various reasons.

of tumor. The surgical radicality and margins were evaluated and examined for the presence of residual tumor which was described by the following classification: R0, no residual tumor and resection margin was $>0 \mathrm{~mm}$; R1, microscopic residual tumor or resection margin was nil; R2, macroscopic residual tumor $(4,20,21)$ or macroscopic unresectable $\mathrm{LN}$ metastasis. All of the patients enrolled in this study underwent resection of lesions with curative (R0) or relatively curative (R1) intention, even when occult distant metastasis within abdomen such as localized peritoneal/diaphragm seeding, and localized omentum metastasis were found. Palliative resection (R2) intention was never suggested to apply before operation, neither was exploratory laparotomy with biopsy, except when the findings of intraoperative exploration were beyond preoperative evaluation of ICC and R0/R1 resection could not be obtained, such as disseminated intrahepatic tumor spread, disseminated peritoneal/diaphragm seeding, diffuse/unresectable fixed LN metastasis with vascular invasion were found beyond preoperative evaluation of ICC, depending on intraoperative assessment of value and safety of surgery. In patients with suspected LN metastasis (preoperative and during operation), liver resection together with lymph node dissection (LND) was performed when possible (regional and extended LND but seldom into the para-aortic regions); liver resection with only lymph node biopsy (LNB) was performed, when diffuse/unresectable fixed LN metastasis with vascular invasion was encountered and the intrahepatic tumor was localized at the same time; LNB was also performed when the primary tumors were unresectable to help to confirm metastasis; in other patients with intrahepatic tumor curatively resected and with no evidence of macroscopic LN enlargement, preventive skeletonization of the hepatoduodenal ligament was performed, with the aim to confirm the stage.

Pathological evaluation. Diagnosis ICC was based on macroscopic examination, H\&E staining, and immunohistochemical study of the resected or biopsy specimens. Pathological characteristics, including tumor size and number, capsule formation, LN metastasis, vascular invasion, perineural invasion and tumor cell differentiation, were collected for all the patients. Each tumor was staged according to AJCC staging system for ICC $(19,22)$, and classified by the category of the gross type of ICC by the Liver Cancer Study Group of Japan (23). Based on 
Table I. Difference between American Joint Committee on Cancer 7th Edition staging system and our staging system for intrahepatic cholangiocarcinoma.

\section{AJCC 7th edition}

Present study

\section{TNM classification}

$\mathrm{T} 1$

$\mathrm{T} 2 \mathrm{a}$

$\mathrm{T} 2 \mathrm{~b}$

T3

$\mathrm{T} 4$

NO

N1

M0

M1

Stage groupings

$\begin{array}{ll}\text { Stage I } & \text { T1 N0 M0 } \\ \text { Stage II } & \text { T2 N0 M0 } \\ \text { Stage III } & \text { T3 N0 M0 } \\ \text { Stage IVA } & \text { T4 N0 M0, Any T N1 M0 } \\ \text { Stage IVB } & \text { AnyTN2-3M0, AnyTN0M1, AnyTN2-3M1 }\end{array}$

\section{TNM classification}

No distant metastasis

Distant metastasis; nodal involvement of

the celiac, periaortic, or caval lymph nodes

(N2-3) is considered to be M1

T1

T2a

$\mathrm{T} 2 \mathrm{~b}$

T3

Tumor perforating the visceral peritoneum or involving local extrahepatic structures by direct invasion

Tumor with periductal invasion ${ }^{\mathrm{b}}$

No regional lymph node metastasis

Regional lymph node metastasis

AnyTN2-3M0, AnyTN0M1, AnyTN2-3M1
Stage groupings

$\begin{array}{ll}\text { Stage I } & \text { T1 N0 M0 } \\ \text { Stage II } & \text { T2 N0 M0 } \\ \text { Stage III } & \text { T3 N0 M0 } \\ \text { Stage IVA } & \text { T4 N0 M0, Any T N1 M0, AnyTN2-3M0 } \\ \text { Stage IVB } & \text { Any T Any N M1 }\end{array}$

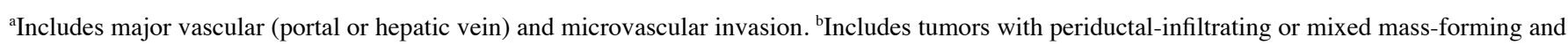
periductal-infiltrating growth pattern.

the factors of LN metastasis and distant metastasis, we divided patients with tumors in stage AJCC-stage IVB into three subgroups according to our new staging system: patients with tumors (AnyTN2-3M0), patients with tumors (AnyTN0-1M1), and patients with tumors (AnyTN2-3M1). Differences of our new staging system and AJCC 7th staging system are listed in Table I.

Follow-up. All patients were followed up by ultrasound scan and tests for liver function and the levels of $\alpha$-fetal protein (AFP), carbohydrate antigen 19-9 (CA19-9) and carcinoembryonic antigen (CEA) at an interval of 1 month for the first year, 1-2 months for the second year, and every 3 months the year after, if there was no recurrence. When tumor recurrences were suspected, CT or MRI scan would be performed to confirm the diagnosis. Treatments of recurrent disease included surgery, transarterial chemoembolization (TACE), radiotherapy, and supportive therapy. Patients were followed for survival until death or the study deadline date of 30 September, 2014.

Statistical analysis. Continuous variables were presented as the mean \pm SD. Independence tests were performed using unpaired t-test for continuous variables and Chi-square or Wilcoxon test for categorical variables. OS rates were calculated with the Kaplan-Meier method. The possible prognostic factors were analyzed by the univariate analysis and evaluated using the Kaplan-Meier method and compared by the log-rank test. The multivariate analysis was performed using the Cox proportional hazards model to identify the independent prognostic factors. Statistical analysis was performed with SPSS for Windows (version 19; SPSS, Inc., Chicago, IL, USA). Statistical significance was defined as $\mathrm{P}<0.05$.

\section{Results}

Demographic and clinicopathological features. Between January 2007 and December 2011, a total of 387 surgically treated patients with mass-forming (MF) type of ICC in AJCC-stage IV were included in this study, among which, 298 patients had ICC in AJCC-stage IVA, while 89 patients were in AJCC-stage IVB. Among patients with ICC in AJCC-stage IVB, 23 patients had ICC in AnyTN2-3M0 stage, 12 patients had ICC in AnyTN0-1M1 stage, and 54 patients had ICC in AnyTN2-3M1 stage according to our new staging 
system. There were $256(66.1 \%)$ males and $131(33.9 \%)$ females, with a mean age of 54.04 \pm 11.17 years (range, 18-82 years). At diagnosis, most patients (76.7\%) had symptoms such as epigastric pain, hepatomegaly and jaundice. In some patients, ICC was accompanied by other concurrent liver diseases, including hepatitis B virus HBV infection (33.1\%), cirrhosis (14.0\%). Elevated serum levels of CA19-9 and/or CEA were detected in $288(74.4 \%)$ cases. At pathological examination, 189 patients $(48.8 \%)$ had solitary tumor whereas 198 patients (51.2\%) had multiple tumors, and the mean tumor size was $7.83 \pm 3.60 \mathrm{~cm}$ (range, $0.4-21.0 \mathrm{~cm}$ ), with a median tumor size of $7.0 \mathrm{~cm}$. ICC with vascular invasion was found in 47 patients (12.1\%), with perineural invasion in 41 patients (10.6\%), and with capsule formation in 2 patients $(0.5 \%)$. Difference of clinicopathological characteristics in the patients with tumors in stage IVA and IVB are listed in Table II, and with more details in Table III.

Surgical results. Of the 387 ICC patients, 343 received liver resection, with an overall resectability rate of $88.7 \%$. R0, R1 and $\mathrm{R} 2$ resections were obtained in 22 (5.7\%), 133 (34.3\%) and $188(48.6 \%)$ patients, respectively, and the remaining $44(11.4 \%)$ patients had only laparotomy and biopsy (tumor and/or LN) because of extensive intrahepatic metastases or peritoneal seeding. LN metastasis occurred in 375 (96.9\%) patients, among which, 154 patients obtained complete LND, including LN around the hepatoduodenal ligament, the left gastric artery, the common hepatic artery, the celiac trunk, and even the para-aortic regions, in addition to liver resection. In other 186 patients with LN metastasis, liver resection with only LNB was performed, which were the mainstay of $\mathrm{R} 2$ resection in this study, with residual tumor in the liver as the second most common cause. The remaining 35 patients with LN metastasis were among those who had only laparotomy exploration and biopsy. In 12 patients without $\mathrm{LN}$ metastasis, 3 patients obtained tumor resection with preventive skeletonization of the hepatoduodenal ligament, the other 9 patients had only laparotomy exploration and biopsy of tumor. Operative death, which was defined as death within 30 days of surgery or death that occurred during same admission period (24), occurred in three cases with an operative mortality of $0.8 \%$. Of the three operative deaths, two cases occurred in IVA group, while the other one occurred in AnyTN2-3M1 group, and all of these cases occurred in $\mathrm{R} 2$ resection group. According to the Clavien-Dindo classification (24), postoperative complications developed in 14 (3.6\%) cases, with 10/298 (3.4\%) in IVA group, 2/23 (8.7\%) in AnyTN2-3M0 group, 1/12 (8.3\%) cases in AnyTN0-1M1 group, and 1/54 (1.9\%) in AnyTN2-3M1 group. Of the cases with postoperative complications, $5 / 133$ cases $(3.8 \%)$ occurred in R1 resection group, $9 / 188$ cases $(4.8 \%)$ occurred in $\mathrm{R} 2$ resection group, and there were no cases in R0 resection group and laparotomy group. Except 3 patients who died of hepatic failure or multiple organ failure, all the patients successfully recovered from the complications.

Adjuvant therapy. Adjuvant chemotherapy was not recommended for patients with R0 resection, while $42.9 \%$ (57) of patients with R1 resection received transarterial chemoembolization (TACE) 4 weeks after surgery and $31.5 \%$ (73) of
Table II. Comparisons of clinicopathological characteristics in the patients with tumors in stage IVA and IVB.

\begin{tabular}{|c|c|c|c|}
\hline Characteristics & IVA (N=298) & IVB $(\mathrm{N}=89)$ & P-value \\
\hline Age (years) & $53.73 \pm 11.43$ & $55.06 \pm 10.23$ & 0.327 \\
\hline Gender & & & 0.774 \\
\hline Male & $196(65.8)$ & $60(67.4)$ & \\
\hline Female & $102(34.2)$ & $29(32.6)$ & \\
\hline HBsAg (+) & $104(34.9)$ & $24(27.0)$ & 0.163 \\
\hline Cirrhosis & $42(14.1)$ & $12(13.5)$ & 0.884 \\
\hline $\begin{array}{l}\text { CA19-9 (+) } \\
\text { and/or CEA (+) }\end{array}$ & $216(72.5)$ & $72(80.9)$ & 0.110 \\
\hline Tumor size $(\mathrm{cm})^{\mathrm{a}}$ & $7.46 \pm 3.46$ & $9.05 \pm 3.81$ & $<0.001$ \\
\hline Tumor number & & & 0.006 \\
\hline Single & $157(52.7)$ & $32(36.0)$ & \\
\hline Multiple & $141(47.3)$ & $57(64.0)$ & \\
\hline Capsule formation & $1(0.3)$ & $1(1.1)$ & 0.363 \\
\hline Lymphatic metastasis & $298(100)$ & $77(86.5)$ & $<0.001$ \\
\hline Vascular invasion & $39(13.1)$ & $8(9.0)$ & 0.299 \\
\hline Perineural invasion & $33(11.1)$ & $8(9.0)$ & 0.575 \\
\hline Surgical margin status & & & $<0.001$ \\
\hline R0 & $22(7.4)$ & $0(0)$ & \\
\hline $\mathrm{R} 1$ & $121(40.6)$ & $12(13.5)$ & \\
\hline $\mathrm{R} 2$ & $141(47.3)$ & $47(52.8)$ & \\
\hline Exploration & $14(4.7)$ & $30(33.7)$ & \\
\hline
\end{tabular}

The data are provided as n (\%) except for age and tumor size which are expressed as mean $\pm \mathrm{SD}$. ${ }^{\mathrm{a} I n}$ cases of multiple tumors, the diameter of the largest nodule represents the size of the tumor.

the patients with unresectable disease or with $\mathrm{R} 2$ resection received adjuvant chemo/radiotherapy. The most common chemotherapy regimen was 5 -fluorouracil (FU) combined with cisplatin and gemcitabine, and three dimensional conformal radiotherapy was the standard radiation therapy that was used mainly for residual positive $\mathrm{LN}$.

\section{Survival}

Tumor stage and and its influence on survival. The median follow-up period was 47 months (range, 1-93 months). The overall 1-, 3- and 5-year survival rates of the whole cohort were $31.3,6.7$ and $1.6 \%$, respectively, with a median survival time (MST) of 8.1 months (range, 1-89 months). The 1-, 3- and 5-year OS rates of patients with stage IVA tumors were 35.9, 7.7 and $1.9 \%$, respectively (MST, 9.0 months); with corresponding rates of 15.7, 3.4 and $0 \%$ for patients with stage IVB tumors, respectively (MST, 5.0 months) ( $\mathrm{P}<0.001$, Fig. 2). The 1-, 3- and 5-year OS rates for patients with stage AnyTN2-3M0 tumors were 30.4, 8.7 and $0.0 \%$, respectively (MST, 9.0 months); much better than 8.3, 0.0 and $0.0 \%$ for patients with stage AnyTNOM1 tumors (MST, 3.0 months) $(\mathrm{P}<0.001$, Fig. 3); and better than $11.1,1.9$ and $0.0 \%$ for patients with stage AnyTN2-3M1 tumors (MST, 4.0 months) $(\mathrm{P}<0.001$, Fig. 3). 
Table III. Comparisons of clinicopathological characteristics in the patients with tumors in different stages (IVA, AnyTN2-3M0, AnyTN0-1M1, and AnyTN2-3M1).

\begin{tabular}{|c|c|c|c|c|c|}
\hline Characteristics & $\begin{array}{c}\text { IVA } \\
(\mathrm{N}=298)\end{array}$ & $\begin{array}{c}\text { AnyTN2-3M0 } \\
(\mathrm{N}=23)\end{array}$ & $\begin{array}{l}\text { AnyTN0-1M1 } \\
\qquad(\mathrm{N}=12)\end{array}$ & $\begin{array}{c}\text { AnyTN2-3M1 } \\
(\mathrm{N}=54)\end{array}$ & P-value \\
\hline Age (years) & $53.73 \pm 11.43$ & $56.52 \pm 9.95$ & $57.50 \pm 6.38$ & $53.89 \pm 10.98$ & 0.472 \\
\hline Gender & & & & & 0.896 \\
\hline Male & $196(65.8)$ & $16(69.6)$ & $9(75.0)$ & $35(64.8)$ & \\
\hline Female & $102(34.2)$ & $7(30.4)$ & $3(25.0)$ & $19(35.2)$ & \\
\hline HBsAg (+) & $104(34.9)$ & $7(30.4)$ & $1(8.3)$ & $16(29.6)$ & 0.248 \\
\hline Cirrhosis & $42(14.1)$ & $6(26.1)$ & $0(0)$ & $6(11.1)$ & 0.162 \\
\hline CA19-9 (+) & $216(72.5)$ & $17(73.9)$ & $8(66.7)$ & $47(87.0)$ & 0.14 \\
\hline \multicolumn{6}{|l|}{ and/or CEA (+) } \\
\hline Tumor size $(\mathrm{cm})$ & $7.46 \pm 3.46$ & $7.60 \pm 2.96$ & $10.69 \pm 3.24$ & $9.31 \pm 4.08$ & $<0.001$ \\
\hline Tumor number & & & & & $<0.001$ \\
\hline Single & $157(52.7)$ & 17 (73.9) & $2(16.7)$ & $13(24.1)$ & \\
\hline Multiple & $141(47.3)$ & $6(26.1)$ & $10(83.3)$ & $41(75.9)$ & \\
\hline Capsule formation & $1(0.3)$ & $0(0)$ & $0(0)$ & $1(1.9)$ & 0.523 \\
\hline Lymphatic metastasis & $298(100)$ & $23(100)$ & $0(0)$ & $54(100)$ & $<0.001$ \\
\hline Vascular invasion & $39(13.1)$ & $6(26.1)$ & $0(0)$ & $2(3.7)$ & 0.021 \\
\hline Perineural invasion & $33(11.1)$ & $4(17.4)$ & $1(8.3)$ & $3(5.6)$ & 0.439 \\
\hline Surgical margin status & & & & & $<0.001$ \\
\hline R0 & $22(7.4)$ & $0(0)$ & $0(0)$ & $0(0)$ & \\
\hline $\mathrm{R} 1$ & $121(40.6)$ & $6(26.1)$ & $1(8.3)$ & $5(9.3)$ & \\
\hline $\mathrm{R} 2$ & $141(47.3)$ & 17 (73.9) & $2(16.7)$ & 28 (51.9) & \\
\hline Exploration & $14(4.7)$ & $0(0)$ & $9(75.0)$ & $21(38.9)$ & \\
\hline
\end{tabular}

The data are provided as $\mathrm{n}(\%)$ except for age and tumor size which are expressed as mean \pm SD.
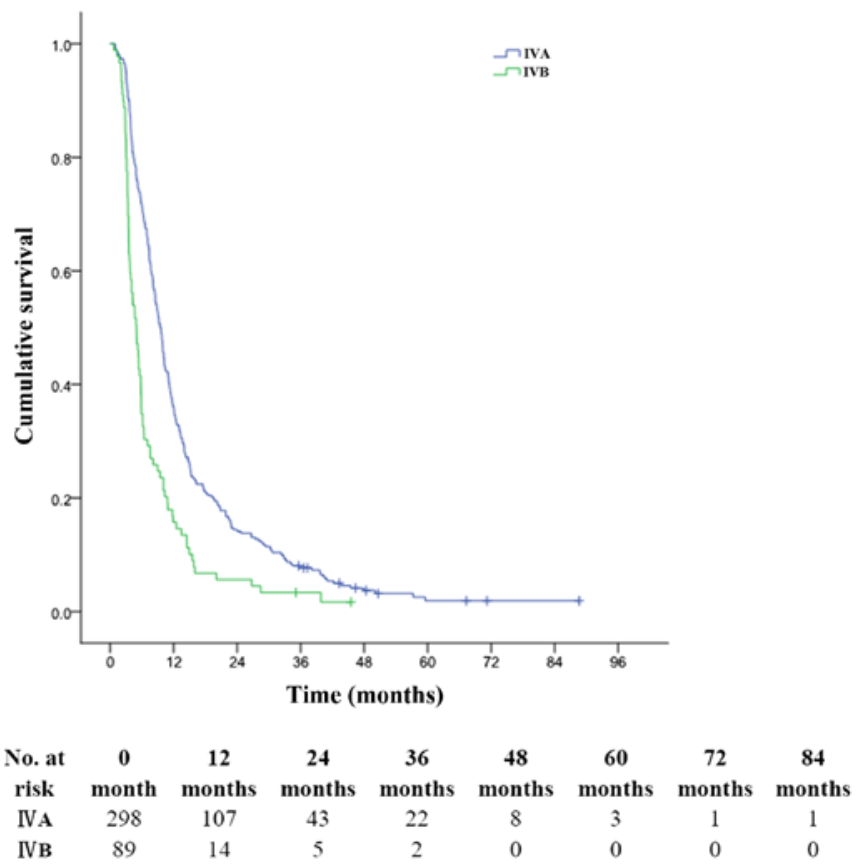

Figure 2. OS for patients with ICC in stage IVA and IVB after surgery. The 1-, 3- and 5-year OS rates for patients with stage IVA tumors were 35.9, 7.7 and $1.9 \%$, respectively, much better than corresponding rates of 15.7 3.4 and $0 \%$ for patients with stage IVB tumors $(\mathrm{P}<0.001)$.
Status of residual tumor after surgery and its influence on survival. In patients with ICC in AJCC-stage IV, those who obtained R0 resection, the 1-, 3- and 5-year OS rates were 68.2, 13.6 and $0 \%$, respectively, with an MST of 14.0 months; while for those who obtained R1 resection, the 1-, 3- and 5-year OS rates were 49.6, 11.9 and 3.3\%, respectively, with an MST of 12.0 months $(\mathrm{P}<0.001$, Fig. 4). The 1-, 3- and 5-year OS rates were $20.7,3.7$ and $1.1 \%$, respectively, in patients with $\mathrm{R} 2$ resection (MST, 6.0 months), much better than 2.3,0.0 and $0.0 \%$ in patients with only exploratory laparotomy and biopsy (MST, 4.0 months) $(\mathrm{P}<0.001$, Fig. 4).

In patients with ICC in AJCC-stage IVA, those who obtained R0 resection, the 1-, 3- and 5-year OS rates were 68.2, 13.6 and $0 \%$, respectively, with an MST of 14.0 months; while for those who obtained R1 resection, the 1-, 3- and 5-year OS rates were 49.6, 11.5 and $3.1 \%$, respectively, with an MST of 12.0 months $(\mathrm{P}<0.001$, Fig. 5). The 1-, 3- and 5-year OS rates were $22.0,4.3$ and $1.4 \%$, respectively, in patients with $\mathrm{R} 2$ resection (MST, 6.0 months), much better than 7.1,0.0 and $0.0 \%$ in patients with only exploratory laparotomy and biopsy (MST, 7.0 months $)(\mathrm{P}<0.001$, Fig. 5).

In patients with ICC in AJCC-stage IVB, nobody obtained $\mathrm{R} 0$ resection in this group, and the 1-, 3- and 5-year OS rates were $50.0,16.7$ and $0.0 \%$, respectively, for those who obtained $\mathrm{R} 1$ resection (MST, 11.0 months). The 1-, 3- and 5-year 


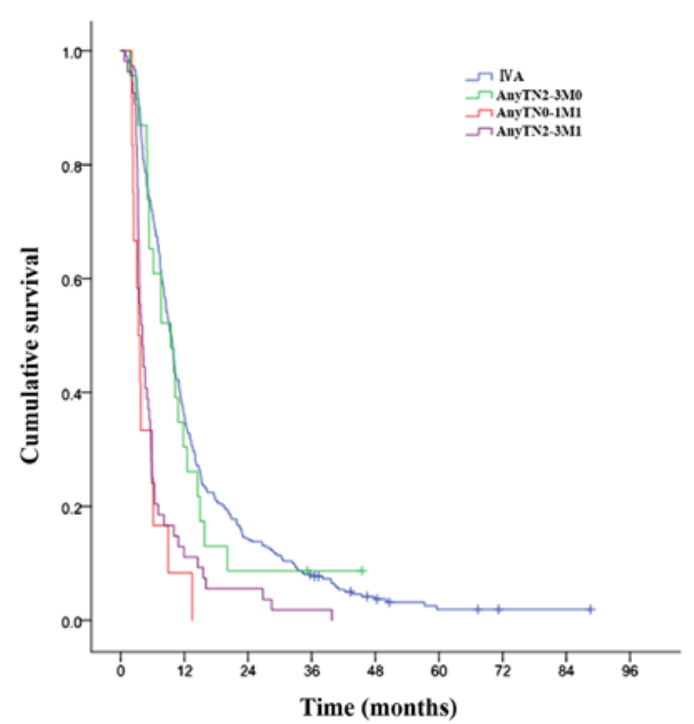

$\begin{array}{ccccccccc}\text { No. at risk } & \begin{array}{c}\mathbf{0} \\ \text { month }\end{array} & \begin{array}{c}\mathbf{1 2} \\ \text { months }\end{array} & \begin{array}{c}\mathbf{2 4} \\ \text { months }\end{array} & \begin{array}{c}\mathbf{3 6} \\ \text { months }\end{array} & \begin{array}{c}\mathbf{4 8} \\ \text { months }\end{array} & \begin{array}{c}\mathbf{6 0} \\ \text { months }\end{array} & \begin{array}{c}\mathbf{7 2} \\ \text { months }\end{array} & \begin{array}{c}\mathbf{8 4} \\ \text { months }\end{array} \\ \text { IVA } & 298 & 107 & 43 & 22 & 8 & 3 & 1 & 1 \\ \text { AnyTN2-3M1 } & 23 & 7 & 2 & 1 & 0 & 0 & 0 & 0 \\ \text { AnyTN0-1M1 } & 12 & 1 & 0 & 0 & 0 & 0 & 0 & 0 \\ \text { AnyTN2-3M1 } & 54 & 6 & 3 & 1 & 0 & 0 & 0 & 0\end{array}$

Figure 3. OS for patients with ICC in different subgroups after surgery. The 1-, 3- and 5-year OS rates for patients with stage IVA tumors were $35.9,7.7$ and $1.9 \%$, respectively, better than corresponding rates of 30.4 , 8.7 and $0 \%$, respectively, for patients with tumors in stage AnyTN2-3M0; much better than $8.3,0$ and $0 \%$, respectively, for patients with tumors in stage AnyTN0-1M1; and than 11.1, 1.9 and $0 \%$, respectively, for patients with tumors in stage AnyTN2-3M1 $(\mathrm{P}<0.001)$.

OS rates were $17.0,2.1$ and $0.0 \%$, respectively, in patients with R2 resection (MST, 5.0 months), much better than 0.0 , 0.0 and $0.0 \%$ in patients with only exploratory laparotomy and biopsy (MST, 3.0 months) (P<0.001, Fig. 6).

Status of the lymph node and its influence on survival. In this study, the patients with LN metastasis had 1-, 3- and 5-year OS rates of 32.0, 6.9 and 1.7\%, respectively (MST, 8.0 months) significantly longer than those without LN who had 1-, 3 - and 5-year OS rates of 8.3, 0 and $0 \%$, respectively (MST, 3.0 months). Among the patients with LN metastasis and without distant metastasis (stage IVA + AnyTN2-3M0), the 1-, 3- and 5-year OS rates were 53.0, 12.7 and 2.8\%, respectively (MST, 13.0 months) for patients undergoing LND, and 20.3, 3.5 and $1.2 \%$, respectively (MST, 7.0 months) for patients who underwent LNB ( $\mathrm{P}<0.001$, Fig. 7).

\section{Discussion}

To the best of our knowledge, this is the largest study involving surgically treated patients with ICC in AJCC-stage IV, so the results of our study would reflect the current profile of surgical treatment of such patients. ICC has been proved to be a highly malignant neoplasm, and extraordinary attention has been paid on the factors that influence the prognosis of ICC following surgical resection in our previous study (25) and other reports $(4,12,15-18,21,26-31)$, but these studies usually related to potential resectable ICC in all stages, and never focused only on ICC in AJCC-stage IV. We would not operate on patients with M1 disease definitely diagnosed

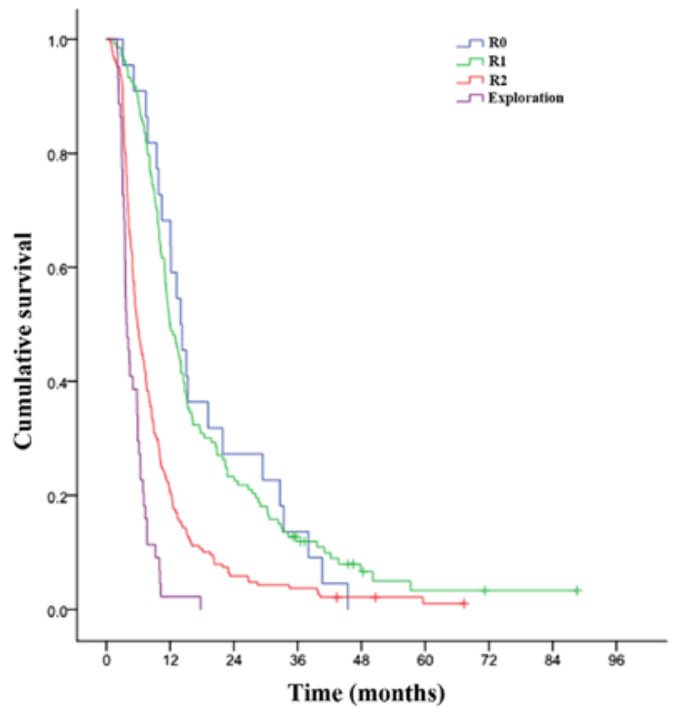

$\begin{array}{ccccccccc}\text { No. at risk } & \begin{array}{c}\mathbf{0} \\ \text { month }\end{array} & \begin{array}{c}\mathbf{1 2} \\ \text { months }\end{array} & \begin{array}{c}\mathbf{2 4} \\ \text { months }\end{array} & \begin{array}{c}\mathbf{3 6} \\ \text { months }\end{array} & \begin{array}{c}\mathbf{4 8} \\ \text { months }\end{array} & \begin{array}{c}\mathbf{6 0} \\ \text { months }\end{array} & \begin{array}{c}\mathbf{7 2} \\ \text { months }\end{array} & \begin{array}{c}\mathbf{8 4} \\ \text { months }\end{array} \\ \mathbf{R} 0 & 22 & 15 & 6 & 3 & 0 & 0 & 0 & 0 \\ \mathbf{R} 1 & 133 & 66 & 31 & 14 & 5 & 2 & 1 & 1 \\ \mathbf{R} 2 & 188 & 39 & 11 & 7 & 3 & 1 & 0 & 0 \\ \text { Exploration } & 44 & 1 & 0 & 0 & 0 & 0 & 0 & 0\end{array}$

Figure 4. OS in ICC patients (tumors in stage IV) with different status of residual tumor. The 1-, 3- and 5-year OS rates were 68.2, 13.6 and $0 \%$, respectively, for patients with $\mathrm{R} 0$ resection; $49.6,11.9$ and $3.3 \%$ for patients with R1 resection; 20.7,3.7 and 1.1\% for patients with $\mathrm{R} 2$ resection; and 2.3, 0.0 and $0.0 \%$ for patients with exploratory laparotomy with biopsy $(\mathrm{P}<0.001)$.

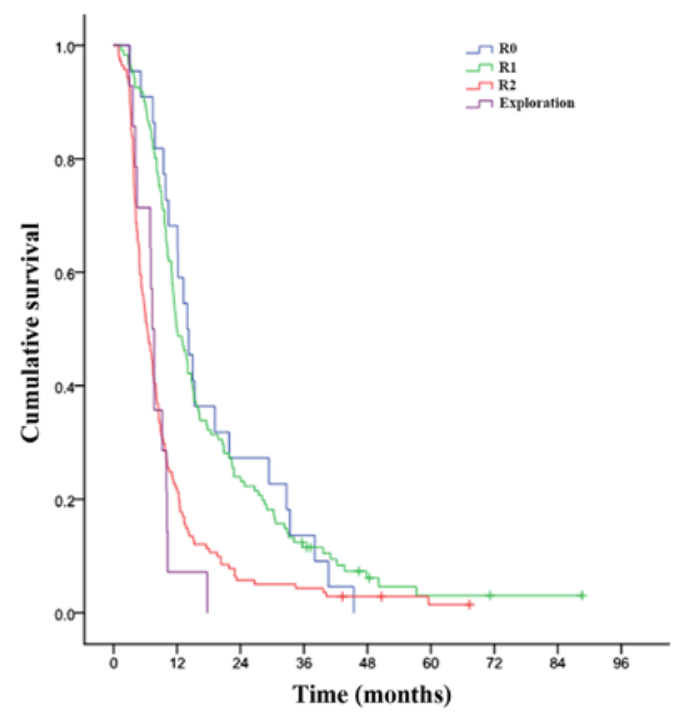

$\begin{array}{ccccccccc}\text { No. at risk } & \begin{array}{c}\mathbf{0} \\ \text { month }\end{array} & \begin{array}{c}\mathbf{1 2} \\ \text { months }\end{array} & \begin{array}{c}\mathbf{2 4} \\ \text { months }\end{array} & \begin{array}{c}\mathbf{3 6} \\ \text { months }\end{array} & \begin{array}{c}\mathbf{4 8} \\ \text { months }\end{array} & \begin{array}{c}\mathbf{6 0} \\ \text { months }\end{array} & \begin{array}{c}\mathbf{7 2} \\ \text { months }\end{array} & \begin{array}{c}\mathbf{8 4} \\ \text { months }\end{array} \\ \text { R0 } & 22 & 15 & 6 & 3 & 0 & 0 & 0 & 0 \\ \text { R1 } & 121 & 60 & 29 & 13 & 5 & 2 & 1 & 1 \\ \text { R2 } & 141 & 31 & 8 & 6 & 3 & 1 & 0 & 0 \\ \text { Exploration } & 14 & 1 & 0 & 0 & 0 & 0 & 0 & 0\end{array}$

Figure 5. OS in ICC patients (tumors in stage IVA) with different status of residual tumor. The 1-, 3- and 5-year OS rates were 68.2, 13.6 and $0 \%$, respectively, for patients with $\mathrm{R} 0$ resection; $49.6,11.5$ and $3.1 \%$ for patients with R1 resection; 22.0, 4.3 and $1.4 \%$ for patients with $\mathrm{R} 2$ resection; and 7.1, 0.0 and $0.0 \%$ for patients with exploratory laparotomy with biopsy $(\mathrm{P}<0.001)$.

before operation, however, occult distant metastasis within abdomen was sometimes found during surgical explora- 


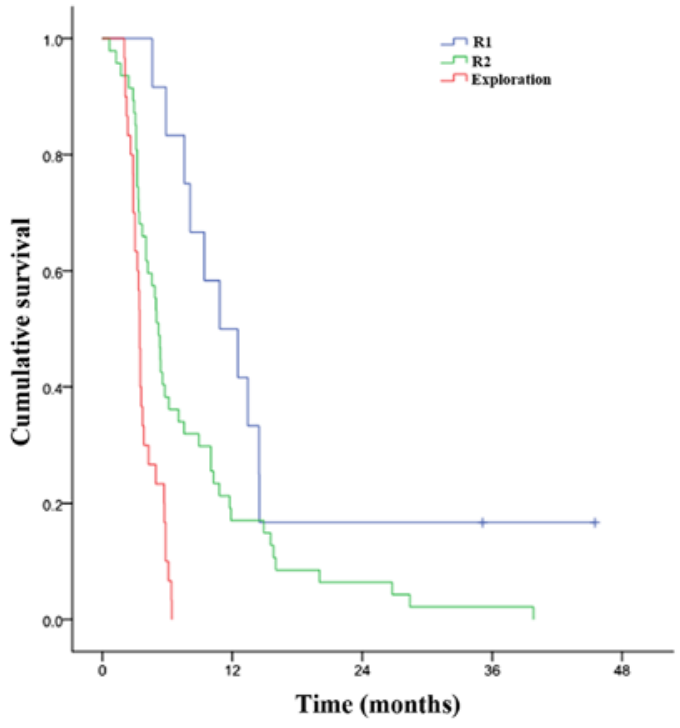

$\begin{array}{ccccc}\text { No. at risk } & \text { 0 month } & \mathbf{1 2} \text { months } & \text { 24 months } & \text { 36 months } \\ \text { R1 } & 12 & 6 & 2 & 1 \\ \text { R2 } & 47 & 8 & 3 & 1 \\ \text { Exploration } & 30 & 0 & 0 & 0\end{array}$

Figure 6. OS in ICC patients (tumors in stage IVB) with different status of residual tumor. The 1-,3- and 5-year OS rates were 50.0, 16.7 and $0.0 \%$, respectively, for patients with R1 resection; 17.0, 2.1 and $0.0 \%$ for patients with R2 resection; and $0.0,0.0$ and $0.0 \%$ for patients with exploratory laparotomy with biopsy $(\mathrm{P}<0.001)$.

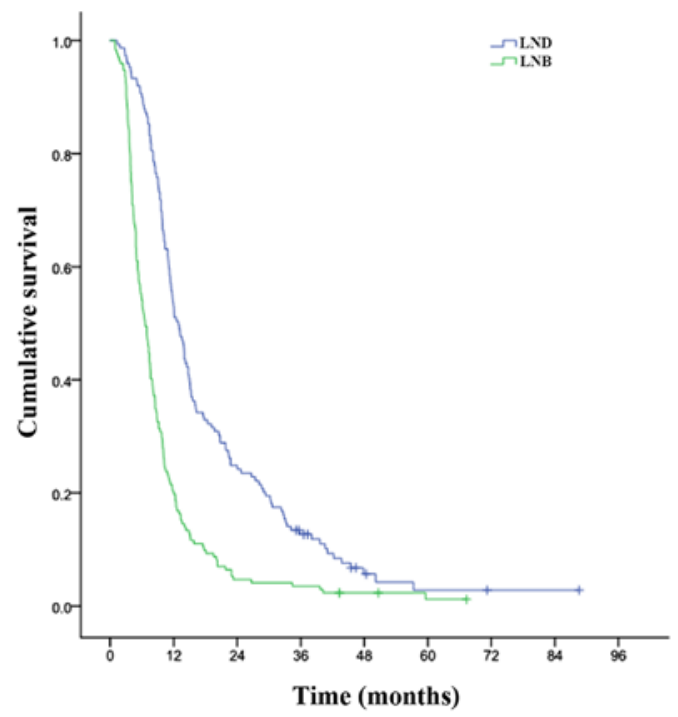

\begin{tabular}{|c|c|c|c|c|c|c|c|c|}
\hline $\begin{array}{c}\text { No. at } \\
\text { risk }\end{array}$ & $\begin{array}{c}0 \\
\text { month }\end{array}$ & $\begin{array}{c}12 \\
\text { months }\end{array}$ & $\begin{array}{c}24 \\
\text { months }\end{array}$ & $\begin{array}{c}36 \\
\text { months }\end{array}$ & $\begin{array}{c}48 \\
\text { months }\end{array}$ & $\begin{array}{c}60 \\
\text { months }\end{array}$ & $\begin{array}{c}72 \\
\text { months }\end{array}$ & $\begin{array}{c}84 \\
\text { months }\end{array}$ \\
\hline LND & 149 & 79 & 37 & 17 & 5 & 2 & 1 & 1 \\
\hline LNB & 172 & 35 & 8 & 6 & 3 & 1 & 0 & 0 \\
\hline
\end{tabular}

Figure 7. OS in ICC patients without distant metastasis (stage IVA + AnyTN2-3M0) and with different surgical management for LN. The 1-, 3- and 5-year OS rates were 53.0, 12.7 and 2.8\%, respectively, for patients undergoing LND; and 20.3, 3.5 and $1.2 \%$, respectively, for patients who underwent LNB $(\mathrm{P}<0.001)$.

tion, and some of such patients obtained resection, thus, it turned out that patients with M1 disease were enrolled in this study. Although patients with ICC in stage IV would rarely undergo a resection in the Western world, our study demonstrated that surgery is still valuable for at least part of these patients, because natural history without any treatment for ICCs in advanced stage was even worse with an MST of only 3.0 months (203 cases) (32), and similiar patients with supportive therapy alone had a MST of 4.9 months (12 cases) (33). An MST of 12.9 months was reported for advanced ICC by palliative chemoradiotherapy (33), which seemed superior than our result (MST, 8.1 months), however, the number of reported patients was small (28 cases) and the evidence was weak. This study demonstrated that the prognosis of ICC in AJCC-stage IV was unfavorable even after surgical management, with an MST of 8.1 months, because compared with the former studies $(4,6,8,11,12,15-18,25,27)$, ICC in this series was more frequently associated with lymph node involvement, multiple tumors, peritoneal dissemination, and low R0 resection rate. However, such patients could definitely benefit from surgery when $\mathrm{R} 0$ or R1 resection was available.

Generally speaking, resection was attempted for ICC whenever possible (3,6-11), leading to varied surgical margin statuses, such as R0, R1, R2 resection, and exploratory laparotomy. Our study, like some reported studies $(6,12,21,34)$, showed that the resection margin status was an independent variable that influenced the prognosis of ICC following surgery. In this series (Fig. 3), surgery was again proven valuable for that R0 resection (MST, 14.0 months) and R1 resection (MST, 12.0 months) provided better survival than $\mathrm{R} 2$ resection (MST, 6.0 months) and non-resective biopsy (MST, 4.0 months). However, R0 resection is not feasible in a considerable proportion especially for ICC cases with tumor in stage IV, and in this study, only $\sim 5.7 \%$ patients obtained R0 resection, much lower than that of our previous study (25) and the literatures (ranging from 19.8 to $80.0 \%)(3-5,12,15-17,21$, 26-31,35,36), owing to different inclusion criteria. However, in present series, the overall resectability rate was $88.7 \%$, which was, to our knowledge, much higher than the reported series including patients with tumors even in earlier stage (ranging from 18 to $77 \%$ ) $(7,8,10,15,17,23,30)$. All these data might account for low $\mathrm{R} 0$ resection rate in this study, which was suggested to be responsible for poor prognosis of ICC in stage IV following surgery, and R0 resection is definitely recommended and valuable when possible for such patients.

In the present study, $\mathrm{R} 1$ resection occurred in $34.4 \%$ of the whole cohort, owing to disadvantageous factors such as large tumors (median size, $7.0 \mathrm{~cm}$ ), multiple tumors $(51.2 \%)$, centrally located tumors, and incomplete tumor capsule with ill-defined borders. Although in this study, R1 resection had significant unfavorable influence on patient survival when compared to R0 resection (MST: 14 months vs 12 months), and although there has been controversy about the effect of $\mathrm{R} 1$ resection on patient survival in the literature $(4,6,12,16,20,21,28,34)$, patients obtained R1 resection survived significantly longer than those with R2 resection or laparotomy (Figs. 4-6). Therefore, R1 resection is recommended when $\mathrm{R} 0$ resection cannot be obtained, not only for its relative curativity but also for ubiquitous unfavorable pathological features of ICC in stage IV.

Previously it was suggested that all types of cancer-directed surgery including palliative surgery may offer a survival advantage over no surgery $(32,37)$. Controversy exists over 
the justification of $\mathrm{R} 2$ resection. Some authors reported that $\mathrm{R} 2$ resection did not provide any survival benefit but only bore the risks of major hepatic surgery $(6,34,38)$, whereas others believed that some patients could benefit from R2 resection $(12,13,36)$. In current series, more than half of the patients with LN metastasis obtained only liver resection with residue positive nodal, which was the most common cause of $\mathrm{R} 2$. Although patients obtained $\mathrm{R} 2$ resection survived a little longer than those undergoing only exploratory laparotomy (MST, 6.0/4.0 months) (Figs. 4-6), it showed no significant advantage over those with chemoradiotherapy, or supportive therapy alone, or without any treatment $(32,33)$. Thus, during surgical exploration, $\mathrm{R} 2$ resection is not recommended.

Up till now, routine lymphadenectomy did not receive unified agreement during surgery especially for ICC in stage IV, not only considering the stage of tumor and the extent of LN metastasis, but also as the debate existed both in the literatures $(9,11,29,39-42)$ and within the surgeons of our hospital for whether such patients could necessarily benefit from standardized LN dissection for prolonged survival. In current series, complete LND was achieved in 154 patients with relatively localized tumors and better range of LN metastasis, while 221 patients underwent LNB because of either diffuse/unresectable fixed LN metastasis or unresectable tumor. Although observations in hilar cholangiocarcinoma (43) and ICC (8) revealed that para-aortic lymphadenectomy may result in improved long-term survival in macroscopically negative but microscopically positive para-aortic LN, extended LN dissection was obtained in celiac trunk, retropancreatic and even into para-aortic regions only in a small number of patients ( $\mathrm{R} 1$ resection in IVB) give consideration to the unsatisfactory surgical radicality of primary liver tumor itself. In this study, results showed that patients with liver resection with LN dissection survived significantly longer than those with LN biopsy for patients without distant metastasis (stage IVA + AnyTN2-3M0), suggesting that LN dissection should be performed when suitable for the benefit of better survival.

Different from former studies $(9,11,25,29,39-42), \mathrm{LN}$ metastasis, one of the key elements constituting AJCC staging system $(19,22)$, was proved to be a favorable prognostic factor for ICC patients only in this series. In fact, there were 375 (96.9\%) patients with LN metastasis in this cohort, with 298 $(100 \%)$ patients in IVA group and $77(86.5 \%)$ patients in IVB group, leading to more advanced stage and worse prognosis for tumors of patients without LN metastasis. On the other hand, in IVB group of this series, patients with extended LN metastasis (N2-3) may not have significantly poorer survival than those with regional (N1) LN metastasis or without LN metastasis (Fig. 2), was inconsistent with current AJCC staging system $(19,22)$, where extended LN metastasis (N2-3) was emphasized as an extremely poor prognostic factor in such a strong way that it was classified as distant metastasis (M1). In this study, we found that, patients in group IVA and/or subgroup AnyTN2-3M0 had better survival than in subgroup AnyTN0-1M1 and/or AnyTN2-3M1, while survival was better in patients in subgroup AnyTN2-3M1 than subgroup AnyTN0-1M1. Survival was similar between patients in group IVA and subgroup AnyTN2-3M0. These results all suggested that M1 was a stronger poor prognostic factor for ICC than extended LN metastasis (N2-3), which was different from opinions of current AJCC staging system $(19,22)$. Moreover, the above data of our study indicated that, using N2-3 instead of M1 to classify extended LN metastasis with involvement of the celiac, periaortic, or caval lymph nodes was more accurate not only in staging ICC but also in estimating survival of patients with ICC

A prognostic and staging system of ICC should be developed based on the outcomes of all the cases for providing guideline on the appropriate of surgery as treatment option. An evaluation of the prognostic accuracy of the 7th edition AJCC staging system is missing for ICC in AJCC-stage IV as yet. Specifically, the $\mathrm{N}$ and $\mathrm{M}$ classification of current AJCC staging system for ICC seemed to be prognostically inaccurate. We use N2-3 instead of M1 for extended LN metastasis classification to stage advanced ICC, thus ICC in stage IVB (AJCC 7th) were divided into three subgroups: AnyTN2-3M0, AnyTN0-1M1, and AnyTN2-3M1. The 1- and 3-year OS for patients in group AnyTN2-3M0 were different but close to group IVA; while the 1- and 5-year OS for patients in group AnyTN0M1 were different but close to group AnyTN2-3M1. Thus, AnyTN2-3M0 should be included in stage IVA, while AnyTN0-1M1 and AnyTN2-3M1 should be included in stage IVB (Table I). This classification was more precise for prediction of outcome in patients with advanced ICC.

However, the current study has several limitations. It is a retrospective single institution study over a 5-year period, during which significant changes in surgical technic, adjuvant therapies and standpoints of surgeons occurred. Our study represents more recent data compared with the former studies in the literature. In addition, there is likely a selection bias; patients with unreconstructable vasculature, significant preoperative comorbidity, and extremely advanced tumor biology (as demonstrated by rapid tumor progression or metastases) were likely not offered resection and thus not included in this study.

In conclusion, liver resections, including $\mathrm{R} 0$ and $\mathrm{R} 1$ resections, could provide survival benefit to the patients with ICC in stage IV. Patients with ICC in stage IVA and AnyTN2-3M0 are candidates for surgery especially when $\mathrm{R} 0$ or $\mathrm{R} 1$ resections could be obtained, not only for safety, but also for possibility of long-term survival in these patients. $\mathrm{R} 2$ resection should be avoided for patients with ICC in both stage IVA and IVB, for whom, surgery should be attempted if there are no sign of M1 before operation, and should be ceased when any evidence of M1 was found during surgical exploration. The current AJCC staging system on $\mathrm{N}$ and $\mathrm{M}$ classification for ICC does not accurately stratify patients with regard to prognosis. Staging of advanced ICC by N2-3 instead of M1 for extended LN metastasis classification is superior in comparison with current AJCC staging system.

\section{References}

1. Sempoux C, Jibara G, Ward SC, Fan C, Qin L, Roayaie S, Fiel MI, Schwartz $M$ and Thung SN: Intrahepatic cholangiocarcinoma: New insights in pathology. Semin Liver Dis 31: 49-60, 2011.

2. Shaib YH, Davila JA, McGlynn K and El-Serag HB: Rising incidence of intrahepatic cholangiocarcinoma in the United States: A true increase? J Hepatol 40: 472-477, 2004.

3. Endo I, Gonen M, Yopp AC, Dalal KM, Zhou Q, Klimstra D, D'Angelica M, DeMatteo RP, Fong Y, Schwartz L, et al: Intrahepatic cholangiocarcinoma: Rising frequency, improved survival, and determinants of outcome after resection. Ann Surg 248: 84-96, 2008. 
4. Tamandl D, Herberger B, Gruenberger B, Puhalla H, Klinger M and Gruenberger T: Influence of hepatic resection margin on recurrence and survival in intrahepatic cholangiocarcinoma. Ann Surg Oncol 15: 2787-2794, 2008.

5. Zhou XD, Tang ZY, Fan J, Zhou J, Wu ZQ, Qin LX, Ma ZC, Sun HC, Qiu SJ, Yu Y, et al: Intrahepatic cholangiocarcinoma: Report of 272 patients compared with 5,829 patients with hepatocellular carcinoma. J Cancer Res Clin Oncol 135: 1073-1080, 2009.

6. Lang H, Sotiropoulos GC, Frühauf NR, Dömland M, Paul A, Kind EM, Malagó $\mathrm{M}$ and Broelsch CE: Extended hepatectomy for intrahepatic cholangiocellular carcinoma (ICC): When is it worthwhile? Single center experience with 27 resections in 50 patients over a 5-year period. Ann Surg 241: 134-143, 2005.

7. Tan JC, Coburn NG, Baxter NN, Kiss A and Law CH: Surgical management of intrahepatic cholangiocarcinoma - a population-based study. Ann Surg Oncol 15: 600-608, 2008.

8. Jonas S, Thelen A, Benckert C, Biskup W, Neumann U, Rudolph B, Lopez-Hänninen E and Neuhaus P: Extended liver resection for intrahepatic cholangiocarcinoma: A comparison of the prognostic accuracy of the fifth and sixth editions of the TNM classification. Ann Surg 249: 303-309, 2009.

9. Ohtsuka M, Ito H, Kimura F, Shimizu H, Togawa A, Yoshidome H and Miyazaki M: Results of surgical treatment for intrahepatic cholangiocarcinoma and clinicopathological factors influencing survival. Br J Surg 89: 1525-1531, 2002.

10. Nakagohri T, Asano T, Kinoshita H, Kenmochi T, Urashima T, Miura F and Ochiai T: Aggressive surgical resection for hilar-invasive and peripheral intrahepatic cholangiocarcinoma. World J Surg 27: 289-293, 2003.

11. Shimada M, Yamashita Y, Aishima S, Shirabe K, Takenaka K and Sugimachi K: Value of lymph node dissection during resection of intrahepatic cholangiocarcinoma. Br J Surg 88: 1463-1466, 2001.

12. Konstadoulakis MM, Roayaie S, Gomatos IP, Labow D, Fiel MI, Miller CM and Schwartz ME: Fifteen-year, single-center experience with the surgical management of intrahepatic cholangiocarcinoma: Operative results and long-term outcome. Surgery 143: 366-374, 2008

13. Lang H, Sotiropoulos GC, Sgourakis G, Schmitz KJ, Paul A, Hilgard P, Zöpf T, Trarbach T, Malagó M, Baba HA, et al: Operations for intrahepatic cholangiocarcinoma: Single-institution experience of 158 patients. J Am Coll Surg 208: 218-228, 2009.

14. Urahashi $\mathrm{T}$, Yamamoto $\mathrm{M}$, Ohtsubo $\mathrm{T}$, Katsuragawa $\mathrm{H}$, Katagiri S and Takasaki K: Hepatopancreatoduodenectomy could be allowed for patients with advanced intrahepatic cholangiocarcinoma. Hepatogastroenterology 54: 346-349, 2007.

15. Wu ZF, Zhang HB, Yang N, Zhao WC, Fu Y and Yang GS Postoperative adjuvant transcatheter arterial chemoembolisation improves survival of intrahepatic cholangiocarcinoma patients with poor prognostic factors: Results of a large monocentric series. Eur J Surg Oncol 38: 602-610, 2012.

16. Cho SY, Park SJ, Kim SH, Han SS, Kim YK, Lee KW, Lee SA, Hong EK, Lee WJ and Woo SM: Survival analysis of intrahepatic cholangiocarcinoma after resection. Ann Surg Oncol 17: $1823-1830,2010$

17. Shen WF, Zhong W, Xu F, Kan T, Geng L, Xie F, Sui CJ and Yang JM: Clinicopathological and prognostic analysis of 429 patients with intrahepatic cholangiocarcinoma. World J Gastroenterol 15: 5976-5982, 2009.

18. Uenishi T, Yamazaki O, Yamamoto T, Hirohashi K, Tanaka H, Tanaka S, Hai S and Kubo S: Serosal invasion in TNM staging of mass-forming intrahepatic cholangiocarcinoma. J Hepatobiliary Pancreat Surg 12: 479-483, 2005.

19. Edge S, Byrd DR, Compton CC, Fritz AG, Greene FL and Trotti A (eds): AJCC Cancer Staging Manual. 7th edition. Springer, New York, NY, 2010.

20. Farges O, Fuks D, Boleslawski E, Le Treut YP, Castaing D, Laurent A, Ducerf C, Rivoire M, Bachellier P, Chiche L, et al: Influence of surgical margins on outcome in patients with intrahepatic cholangiocarcinoma: A multicenter study by the AFC-IHCC-2009 study group. Ann Surg 254: 824-829, discussion 830, 2011.

21. Shimada K, Sano T, Sakamoto Y, Esaki M, Kosuge T and Ojima H: Clinical impact of the surgical margin status in hepatectomy for solitary mass-forming type intrahepatic cholangiocarcinoma without lymph node metastases. J Surg Oncol 96: 160-165, 2007.
22. Edge SB and Compton CC: The American Joint Committee on Cancer: The 7th edition of the AJCC cancer staging manual and the future of TNM. Ann Surg Oncol 17: 1471-1474, 2010.

23. Liver Cancer Study Group of Japan: The general rules for the clinical and pathological study of primary liver cancer. Jpn J Surg 19: 98-129, 1989 .

24. Clavien PA, Barkun J, de Oliveira ML, Vauthey JN, Dindo D, Schulick RD, de Santibañes E, Pekolj J, Slankamenac K, Bassi C, et al: The Clavien-Dindo classification of surgical complications: Five-year experience. Ann Surg 250: 187-196, 2009.

25. Luo X, Yuan L, Wang Y, Ge R, Sun Y and Wei G: Survival outcomes and prognostic factors of surgical therapy for all potentially resectable intrahepatic cholangiocarcinoma: A large single-center cohort study. J Gastrointest Surg 18: 562-572, 2014

26. Wang Y, Li J, Xia Y, Gong R, Wang K, Yan Z, Wan X, Liu G, Wu D, Shi L, et al: Prognostic nomogram for intrahepatic cholangiocarcinoma after partial hepatectomy. J Clin Oncol 31: $1188-1195,2013$

27. Tamandl D, Kaczirek K, Gruenberger B, Koelblinger C, Maresch J, Jakesz R and Gruenberger T: Lymph node ratio after curative surgery for intrahepatic cholangiocarcinoma. $\mathrm{Br}$ J Surg 96: 919-925, 2009.

28. Paik KY, Jung JC, Heo JS, Choi SH, Choi DW and Kim YI: What prognostic factors are important for resected intrahepatic cholangiocarcinoma? J Gastroenterol Hepatol 23: 766-770, 2008.

29. Uchiyama K, Yamamoto M, Yamaue H, Ariizumi S, Aoki T, Kokudo N, Ebata T, Nagino M, Ohtsuka M, Miyazaki M, et al: Impact of nodal involvement on surgical outcomes of intrahepatic cholangiocarcinoma: A multicenter analysis by the Study Group for Hepatic Surgery of the Japanese Society of Hepato-Biliary-Pancreatic Surgery. J Hepatobiliary Pancreat Sci 18: 443-452, 2011

30. Shirabe K, Mano Y, Taketomi A, Soejima Y, Uchiyama H, Aishima S, Kayashima H, Ninomiya $M$ and Maehara $Y$ : Clinicopathological prognostic factors after hepatectomy for patients with mass-forming type intrahepatic cholangiocarcinoma: Relevance of the lymphatic invasion index. Ann Surg Oncol 17: 1816-1822, 2010.

31. de Jong MC, Nathan H, Sotiropoulos GC, Paul A, Alexandrescu S, Marques H, Pulitano C, Barroso E, Clary BM, Aldrighetti L, et al: Intrahepatic cholangiocarcinoma: An international multi-institutional analysis of prognostic factors and lymph node assessment. J Clin Oncol 29: 3140-3145, 2011.

32. Park J, Kim MH, Kim KP, Park H, Moon SH, Song TJ, Eum J, Lee SS, Seo DW and Lee SK: Natural History and Prognostic Factors of Advanced Cholangiocarcinoma without Surgery, Chemotherapy, or Radiotherapy: A Large-Scale Observational Study. Gut Liver 3: 298-305, 2009.

33. Dhanasekaran R, Hemming AW, Zendejas I, George T, Nelson DR, Soldevila-Pico C, Firpi RJ, Morelli G, Clark V and Cabrera R: Treatment outcomes and prognostic factors of intrahepatic cholangiocarcinoma. Oncol Rep 29: 1259-1267, 2013.

34. Puhalla H, Schuell B, Pokorny H, Kornek GV, Scheithauer W and Gruenberger T: Treatment and outcome of intrahepatic cholangiocellular carcinoma. Am J Surg 189: 173-177, 2005.

35. Zhou HB, Wang H, Li YQ, Li SX, Wang H, Zhou DX, Tu QQ, Wang Q, Zou SS, Wu MC, et al: Hepatitis B virus infection: A favorable prognostic factor for intrahepatic cholangiocarcinoma after resection. World J Gastroenterol 17: 1292-1303, 2011.

36. Jiang BG, Sun LL, Yu WL, Tang ZH, Zong M and Zhang YJ: Retrospective analysis of histopathologic prognostic factors after hepatectomy for intrahepatic cholangiocarcinoma. Cancer J 15: 257-261, 2009 .

37. Karpeh MS Jr: Palliative treatment and the role of surgical resection in gastric cancer. Dig Surg 30: 174-180, 2013.

38. Suh KS, Chang SH, Lee HJ, Roh HR, Kim SH and Lee KU: Clinical outcomes and apomucin expression of intrahepatic cholangiocarcinoma according to gross morphology. J Am Coll Surg 195: 782-789, 2002.

39. DeOliveira ML, Cunningham SC, Cameron JL, Kamangar F, Winter JM, Lillemoe KD, Choti MA, Yeo CJ and Schulick RD: Cholangiocarcinoma: Thirty-one-year experience with 564 patients at a single institution. Ann Surg 245: 755-762, 2007.

40. Inoue K, Makuuchi M, Takayama T, Torzilli G, Yamamoto J, Shimada K, Kosuge T, Yamasaki S, Konishi M, Kinoshita T, et al: Long-term survival and prognostic factors in the surgical treatment of mass-forming type cholangiocarcinoma. Surgery 127: 498-505, 2000. 
41. Patel T: Increasing incidence and mortality of primary intrahepatic cholangiocarcinoma in the United States. Hepatology 33: 1353-1357, 2001.

42. Grobmyer SR, Wang L, Gonen M, Fong Y, Klimstra D, D'Angelica M, DeMatteo RP, Schwartz L, Blumgart LH and Jarnagin WR: Perihepatic lymph node assessment in patients undergoing partial hepatectomy for malignancy. Ann Surg 244: 260-264, 2006
43. Kitagawa Y, Nagino M, Kamiya J, Uesaka K, Sano T, Yamamoto $\mathrm{H}$, Hayakawa $\mathrm{N}$ and Nimura Y: Lymph node metastasis from hilar cholangiocarcinoma: Audit of 110 patients who underwent regional and paraaortic node dissection. Ann Surg 233: 385-392, 2001 . 